\title{
Fulfill Your Digital Preservation Goals with a Budget Studio
}

\section{ABSTRACT}

To fulfill digital preservation goals, many institutions use high-end scanners for in-house scanning of historical print and oversize materials. However, high-end scanner prices do not fit in many small institutions' budgets. As digital single-lens reflex (DSLR) camera technologies advance and camera prices drop quickly, a budget photography studio can help to achieve institutions' preservation goals. This paper compares images delivered by a high-end overhead scanner and a consumer-level DSLR camera, discusses pros and cons of using each method, demonstrates how to set up a cost-efficient shooting studio, and presents a budget estimate for a studio.

\section{INTRODUCTION}

Colorado State University Libraries (CSUL) are regularly engaged in a variety of digitization projects. Materials for some projects are digitized in-house, while items from selected projects are sometimes outsourced. Most fragile materials that require professional handling are digitized inhouse using an expensive overhead scanner. However, the overhead scanner has been occasionally unstable since it was purchased, and this has delayed some of our digitization projects. As digital photography technologies advance, image quality delivered by digital singlelens reflex (DSLR) cameras is improving, and camera prices have lowered to an affordable level. In this paper, I will compare images produced by a scanner and a camera side-by-side, list pros and cons of using each method, illustrate how to establish a shooting studio, and present a budget estimate for that studio.

\section{LITERATURE REVIEW}

There are many online guidelines and manuals for digitizing print materials. Some universities and museums have information about their digitization equipment online. Most articles focus on either high-end scanners or customized scanning stations. These articles are very helpful for universities and museums that are relatively well funded. However, there is almost no literature discussing how to use inexpensive digital cameras and photography equipment to produce highquality digitized images. This article will use a case study to prove that a low-budget studio can produce high-quality digitized images.

\section{COMPARISON OF SCANNED AND PHOTOGRAPHED IMAGES}

The test camera set was chosen because it was the one the author used for general purpose. The camera was also chosen by many professional photographers because of its quality and

Yongli Zhou (yongli.zhou@colostate.edu) is Digital Repositories Librarian, Colorado State University Libraries, Fort Collins, Colorado. 
affordability. To avoid dispute, the overhead scanner's make and model are not revealed.

\section{Test Equipment}

\section{Budget Studio Overhead Scanner}

- Nikon D800

- Nikon AF Micro-Nikkor 60mm f/2.8D Lens

- Manfrotto 055CXPR03 3-Section Carbon Fiber Tripod Legs

- Really Right Stuff BH-40 LR II Ballhead

- Nonreflective glass

- Book cradles

- X-Rite Original ColorChecker Card

- Natural daylight

- Total cost: $\mathbf{\$ 4 , 5 0 0}$ and no maintenance fees (priced in 2014)

Table 1. Test Equipment

\section{Focus and Sharpness}

A quality digitized image needs to have a good focus. A well-focused image shows details better and can produce better Optical Character Recognition (OCR) results for text-based documents. At CSUL, we have no control over the automatic focus on our overhead scanner and have noticed that sometimes one page is sharply focused but the next page is slightly out-of-focus. During the scanning process, our overhead scanner does not indicate if a shot is focused or not. A DSLR camera can beep or display a flashing dot on the viewfinder when in focus.

\section{Illustration}

The following two figures compare images produced by our test DSLR and overhead scanner. Both images were originals and have not been enhanced by software. In addition to this image, we tested nine other illustrations. Following our comparison study, we concluded that a semiprofessional DSLR camera produces sharper images than our expensive overhead scanner. In figure 1, at 100 percent zoom, the left image has a better focus, contains more details, and has colors closer to the original. The left image was taken using a Nikon D800 + Nikkor 60mm macro lens and under natural lighting. The right image was produced by our overhead scanner.

In Figure 2, at 200 percent zoom, the left image (taking using the DSLR) shows much more detail than the image on the right (taken with the overhead scanner). 


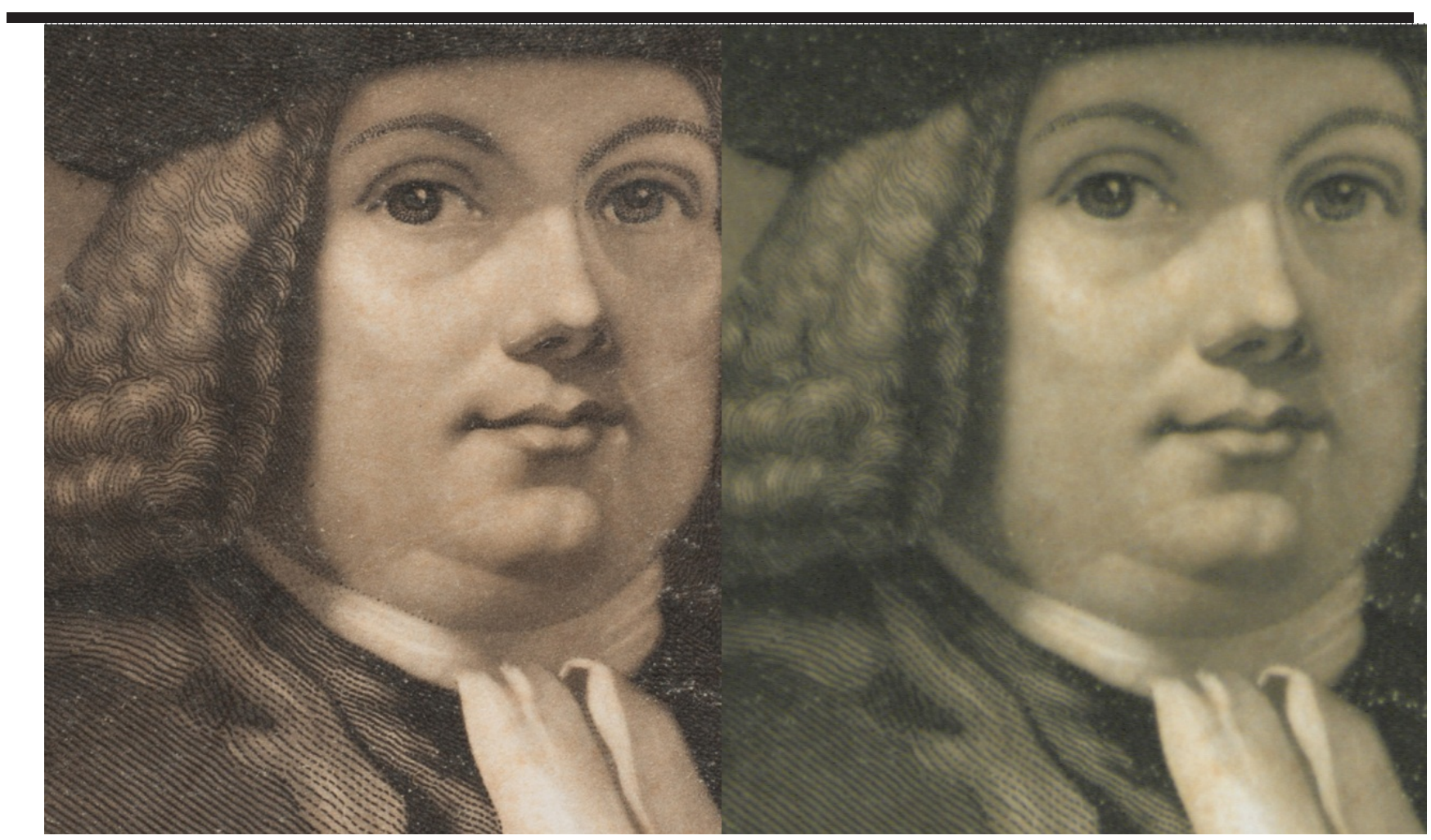

Figure 1. Comparative Images from DSLR (Left) and Overhead Scanner (Right), at 100 Percent Zoom. Image from Samuel M. Janney, The Life of William Penn; with Selections from His Correspondence and Auto-Biography (Philadelphia: Hogan Perkins \& CO, 1852), plate between pages 296 and 297.

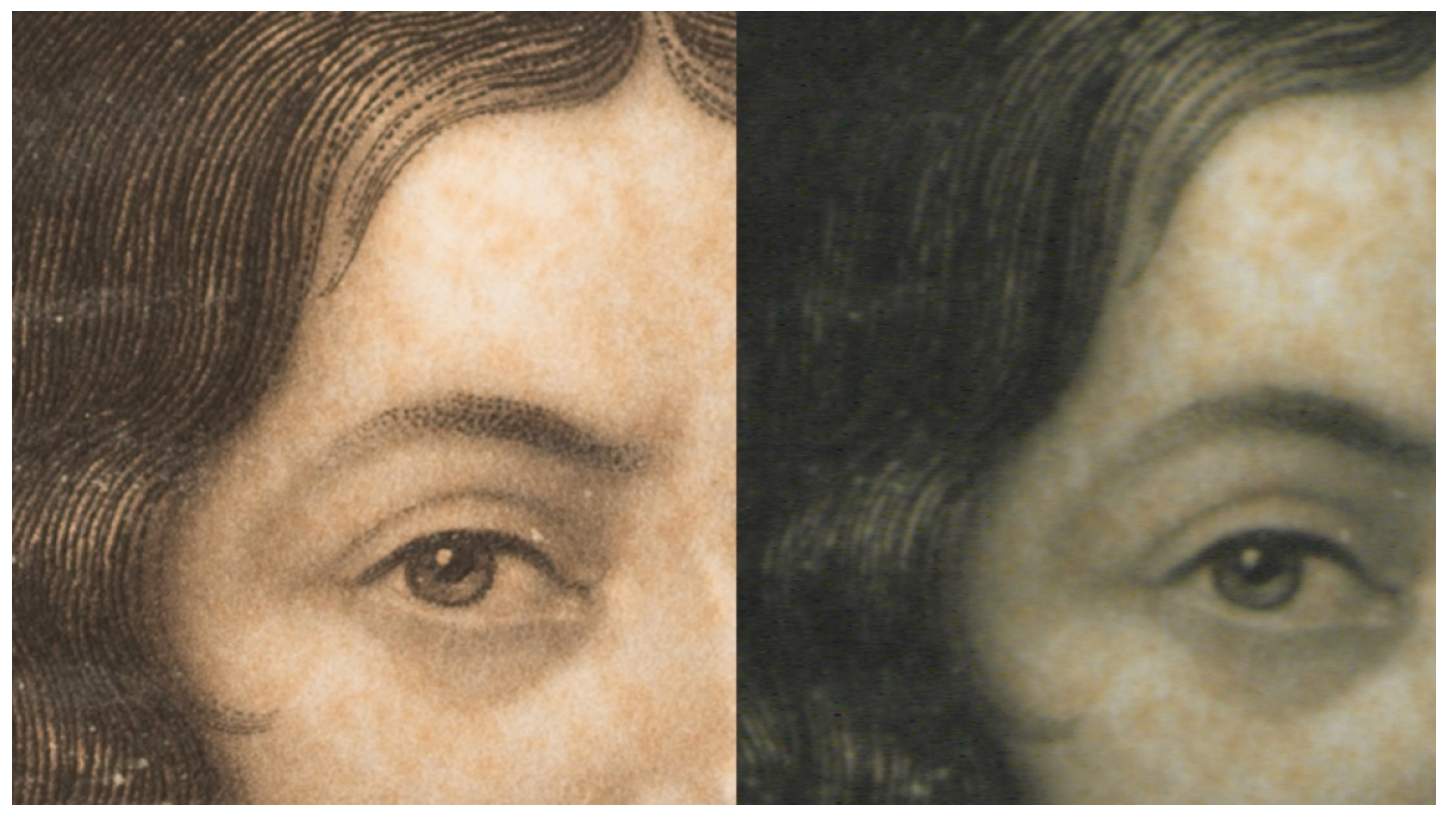

Figure 2. Comparative Images from DSLR (Left) and Overhead Scanner (Right), at 200 Percent Zoom. Image from Samuel M. Janney, The Life of William Penn; with Selections from His 
Correspondence and Auto-Biography (Philadelphia: Hogan Perkins \& CO, 1852), frontispiece, print.

At CSUL, the process of digitizing a text document includes scanning pages, converting them into Portable Document Format (PDF) files, and applying an OCR process. In general, a well-focused image of text produces better OCR results, although software such as Adobe Acrobat can tolerate fuzzy images and produce reasonably accurate OCR text. Our OCR tests from a slightly out-of-focus image and a well-focused image have no significant difference; however, from preservation and usability standpoints, we prefer well-focused images.

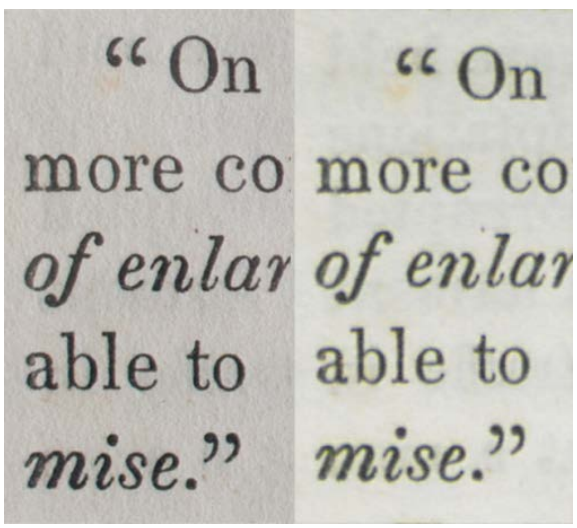

Figure 3. The left image was produced by our test DSLR camera and has a better focus. The right image was produced by our overhead scanner. Samuel M. Janney, The Life of William Penn; with Selections from His Correspondence and Auto-Biography (Philadelphia: Hogan Perkins \& CO, 1852), 300, print.

" On one or two points of high importance, he had notions more correct than were, in his day, common, even among men of enlarged minds, and he had the rare good fortune of being able to carry his theories into practice without any compromise." Yet, "he was not a man of strong sense."

" On one or two points of high importance, he had notions more correct than were, in his day, common, even among men of enlarged minds, and he had the rare good fortune of being able to carry his theories into practice without any compromise." Yet, "he was not a man of strong sense."

Figure 4. We ran the OCR process on the above two images. The top image was produced by our test DSLR camera and the bottom image was produced by our overhead scanner. Samuel M. 
Janney, The Life of William Penn; with Selections from His Correspondence and Auto-Biography (Philadelphia: Hogan Perkins \& CO, 1852), 300, print.

\begin{tabular}{|c|c|}
\hline Generated from the Image by Camera & Generated from the Image by Scanner \\
\hline $\begin{array}{l}\text { " On one or two points of high importance, he } \\
\text { had notions more correct than were, in his } \\
\text { day, common, even among men of } \mathbf{e} 1 \text { larged } \\
\text { minds, and he had the rare good fortune of } \\
\text { being able to carry his theories into practice } \\
\text { without any compromise."Yet, "he was not a } \\
\text { man of stron sense." }\end{array}$ & $\begin{array}{l}\text { " On one or two points of high importance, he } \\
\text { bad notions more correct than were, in his } \\
\text { day, common, even arnong men of } \\
\text { e1 larged minds, and he had the rare good } \\
\text { fortune of being able to carry his theories into } \\
\text { practice without any compromise." Yet, "he } \\
\text { was not a man of strong sense." }\end{array}$ \\
\hline
\end{tabular}

Table 2. OCR Results Comparison

These test results are very close because of the forgiveness of the Adobe Acrobat software. However, we have seen that for some other pages, a better-focused image generates improved OCR results.

\section{Photograph}

A 6.5 inches by 4.5 inches silver print was used for this test. Our tests show that the test DSLR camera produced a sharper image of this historic photograph.

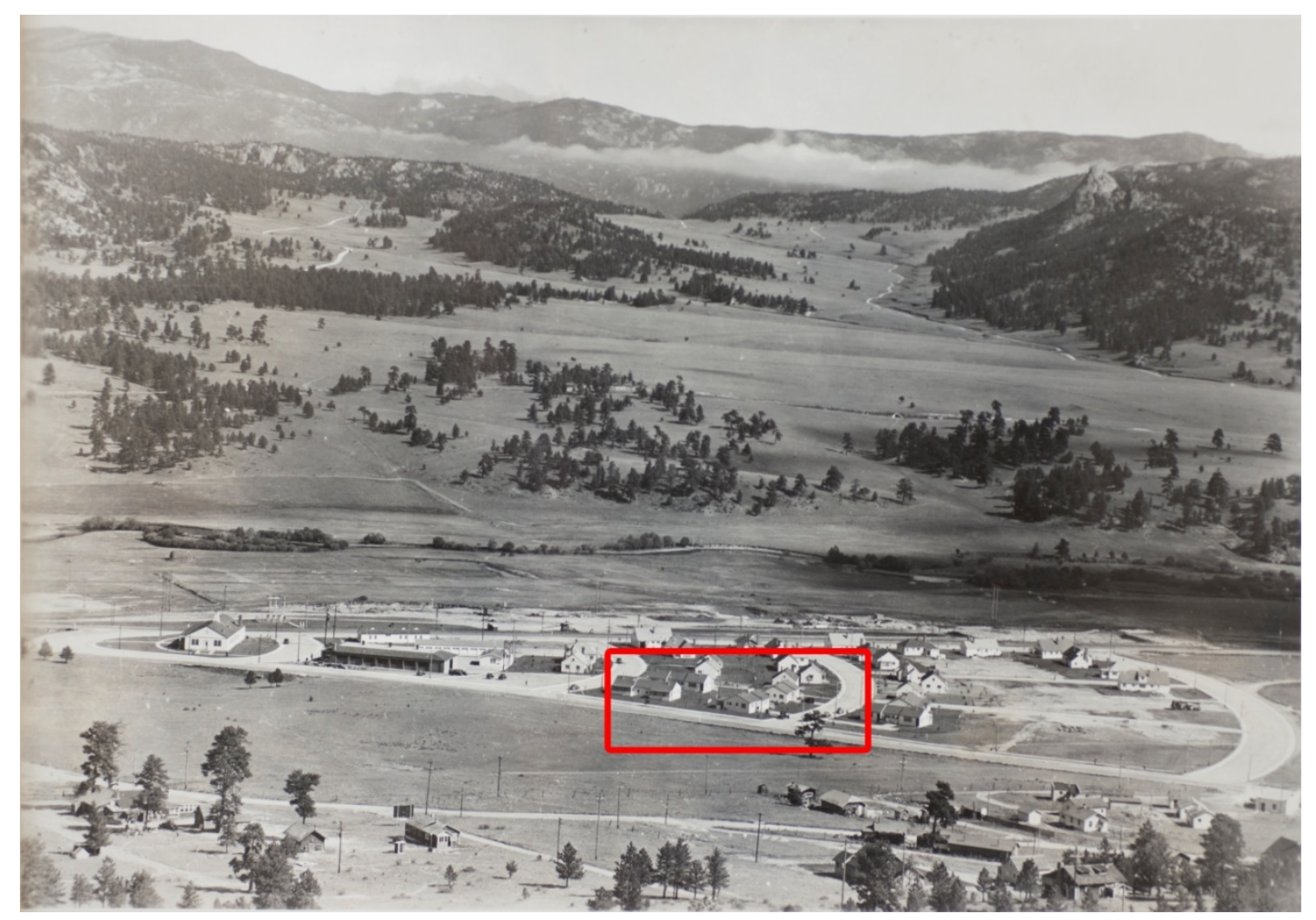


Figure 5. Tested 6.5 Inches by 4.5 Inches Photograph. The red square indicates the enlarged area for figure 6. Historical photograph from Colorado State University Archives and Special Collections.

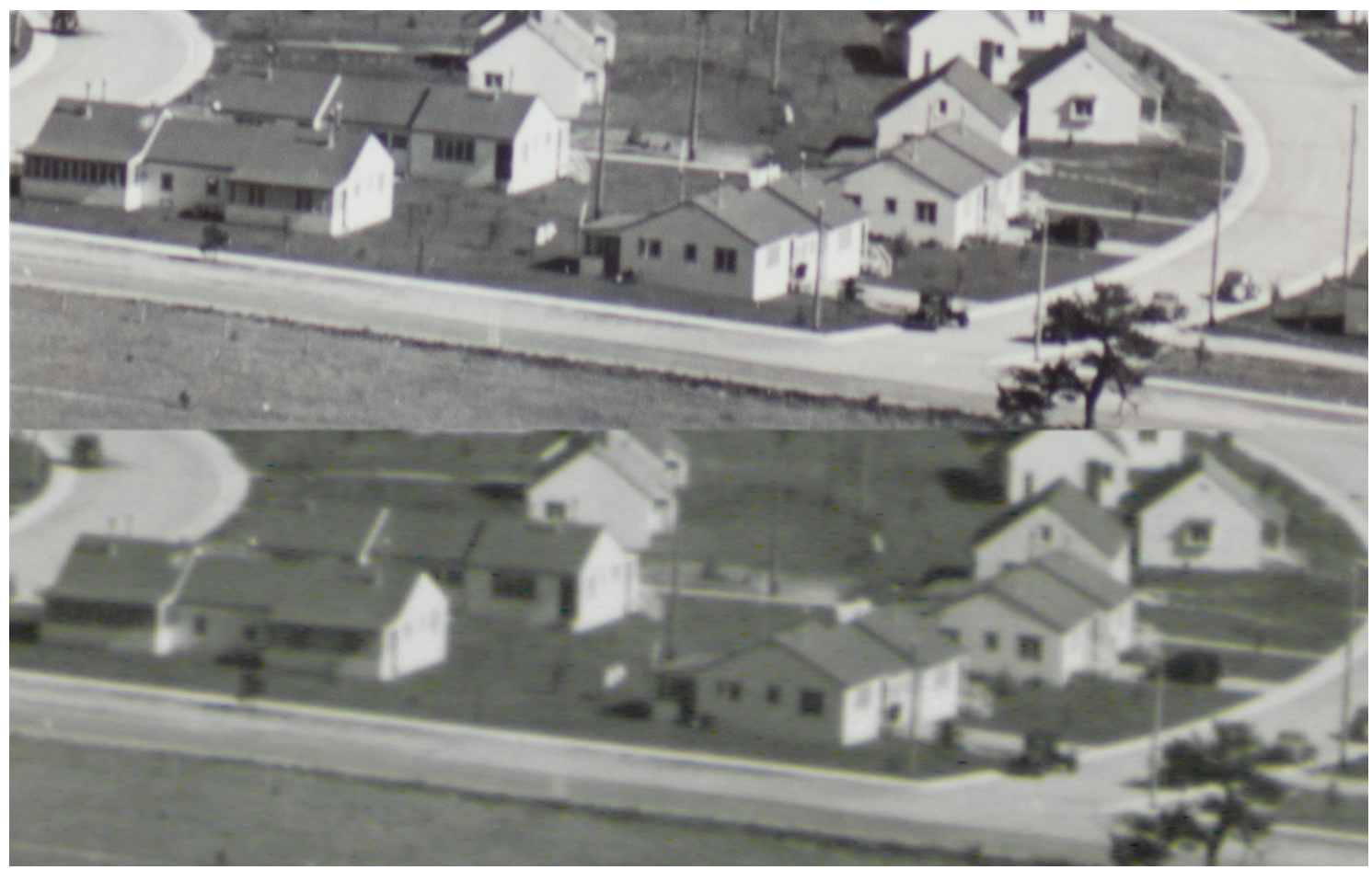

Figure 6. Screen View at 100 Percent Zoom of a Silver Print. The top image was produced by the test DSLR camera and the bottom one was produced by our overhead scanner. Historical photograph from Colorado State University Archives and Special Collections.

\section{Oversize Materials}

For oversized materials, overhead scanners and DSLR cameras have their drawbacks, so we do not think either option is ideal for them. Our library uses a map scanner to scan oversize maps and posters. However, a map scanner is expensive and may not fit many libraries' budgets. A map scanner also is not suitable for fragile maps or posters.

Our overhead scanner's maximum scanning area is 24 inches by 17 inches, and the test map's size is 25 inches by 26 inches. We had to scan the map in four sections and stitch them together using Adobe Photoshop. Each section image has a files size of 313 MB. Because of large file sizes, the stitching process is extremely slow. Also stitching images is not recommended because there are always some degrees of mismatching errors created by lens distortion.

A camera can capture any material size, but the details of the photographed images diminish as the material's size increases. The photo of the entire map taken by our test DLSR has a file size of 35.8 MB. The image produced by camera has a lower resolution and less detail. 


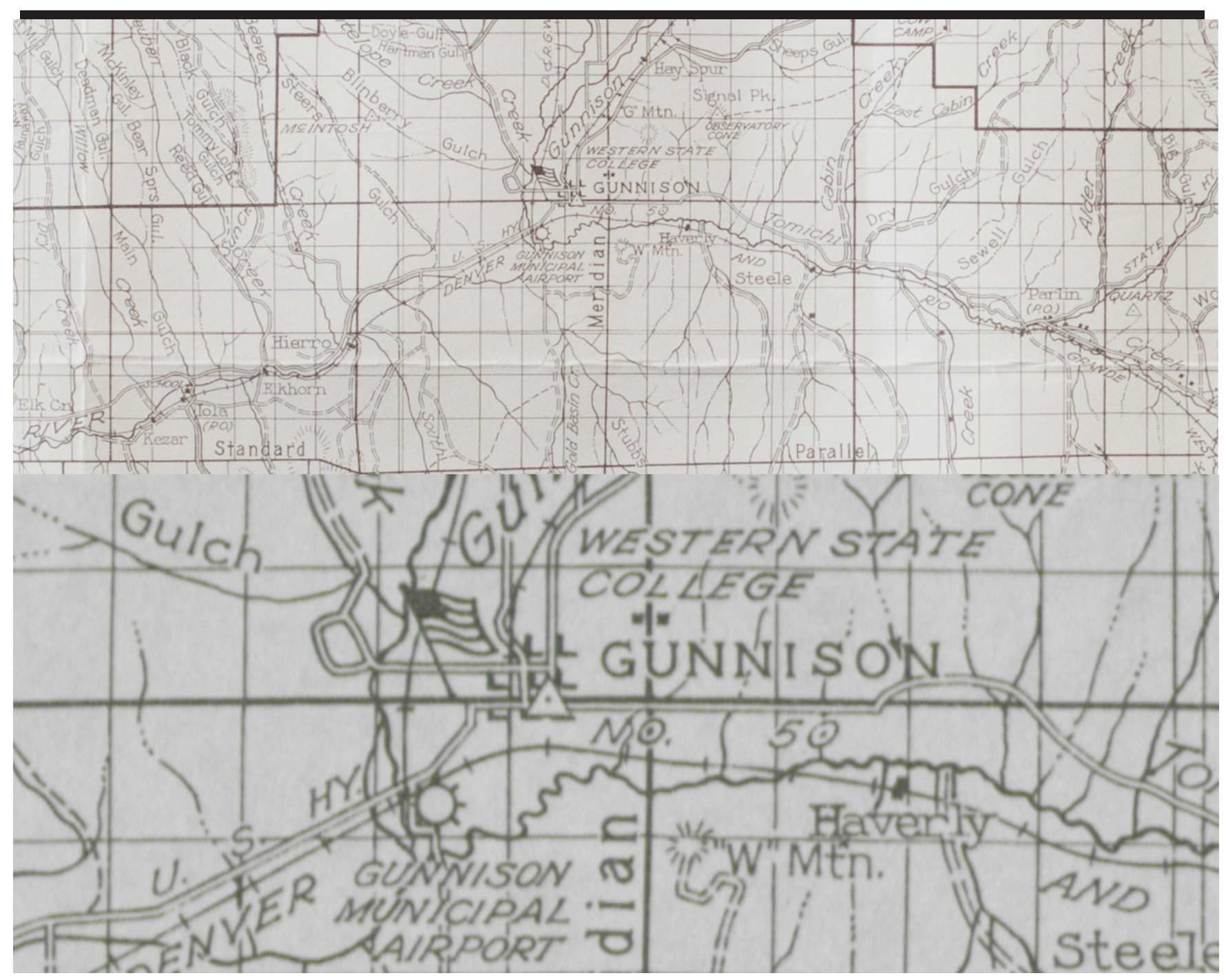

Figure 7. Oversized Materials Screen View at 100 Percent Zoom. The top image was photographed by the test DSLR. The bottom image was scanned by our overhead scanner. Historical map from Colorado State University Archives and Special Collections.

\section{Small Prints}

One big advantage of a DSLR camera is that it can be set farther away to take pictures of oversized materials or very close to smaller objects to take close-up pictures. Comparatively, the distance of lens and scanning platform on our overhead scanner is fixed, so no close-up images can be produced, and everything is reproduced at scale of 1:1.

For the following example, we used a 5.5 inches by 3.5 inches drawing as our test subject. 


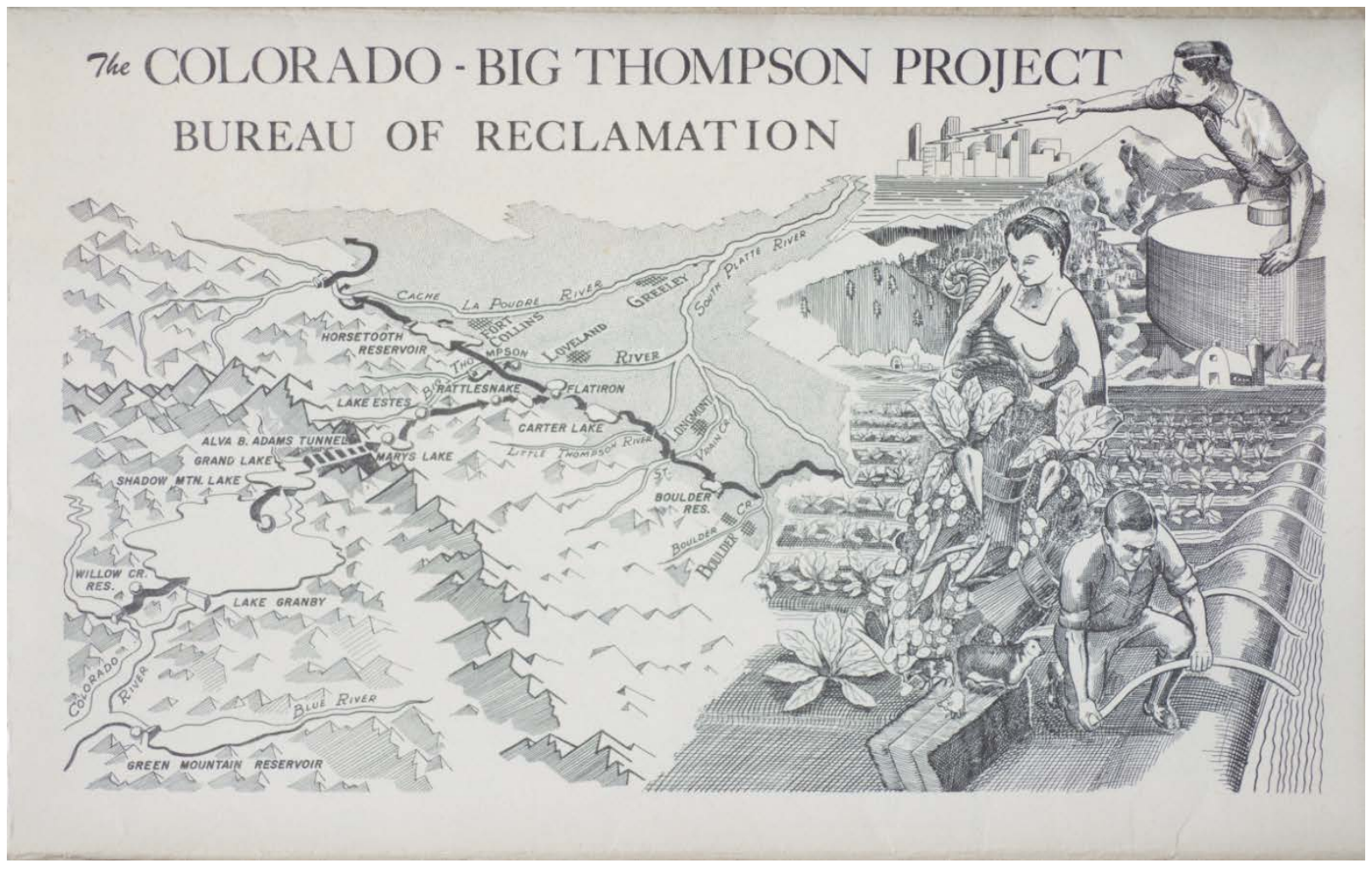

Figure 8. A 5.5 inches by 3.5 inches Fine Drawing. A historical booklet from Colorado State University Archives and Special Collections.

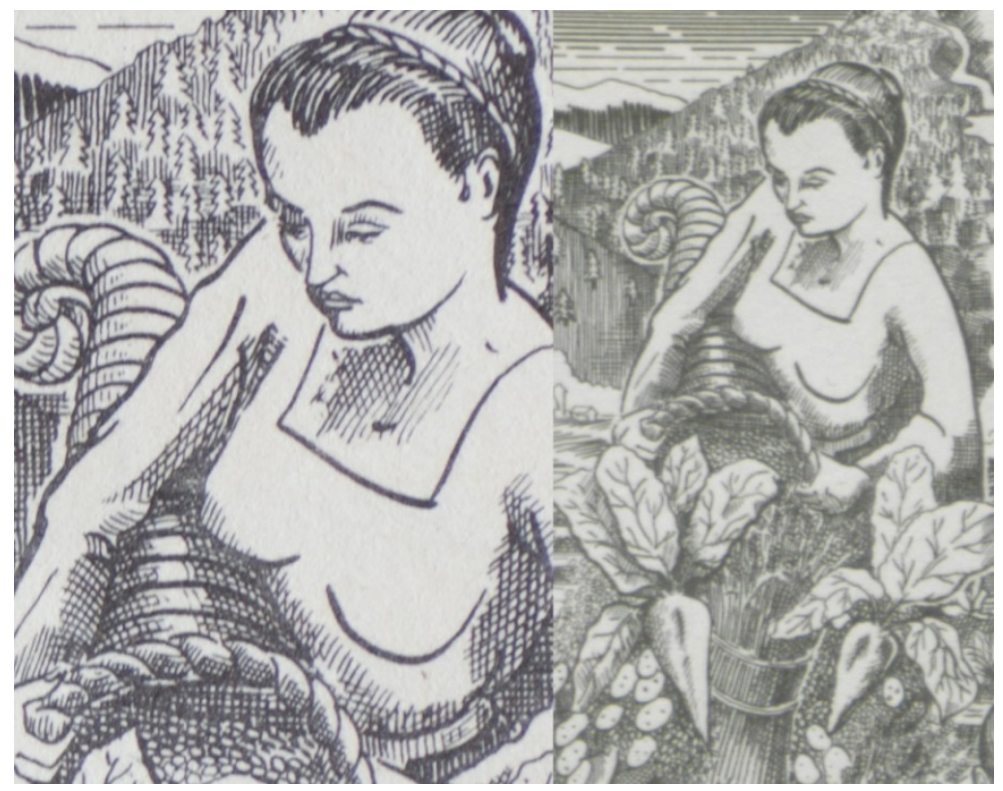

Figure 9. Small Prints Screen View at 100 Percent Zoom. The left image is produced by a DSLR with a macro lens and the right image was scanned by our overhead scanner. A historical booklet from Colorado State University Archives and Special Collections. 
The image produced by our overhead scanner has a resolution of 3,427 pixels by 2,103 pixels. The camera produces a 6,776 pixels by 4,240 pixels image. The higher pixel count allows users to see more details at the same zoom level. The image produced by camera is not only sharper but also contains more details. It also is good for making enlarged prints for promotion materials.

For smaller maps, a DSLR camera also produces superior images. For the following sample, we tested a 15 inches by 9.5 inches map.

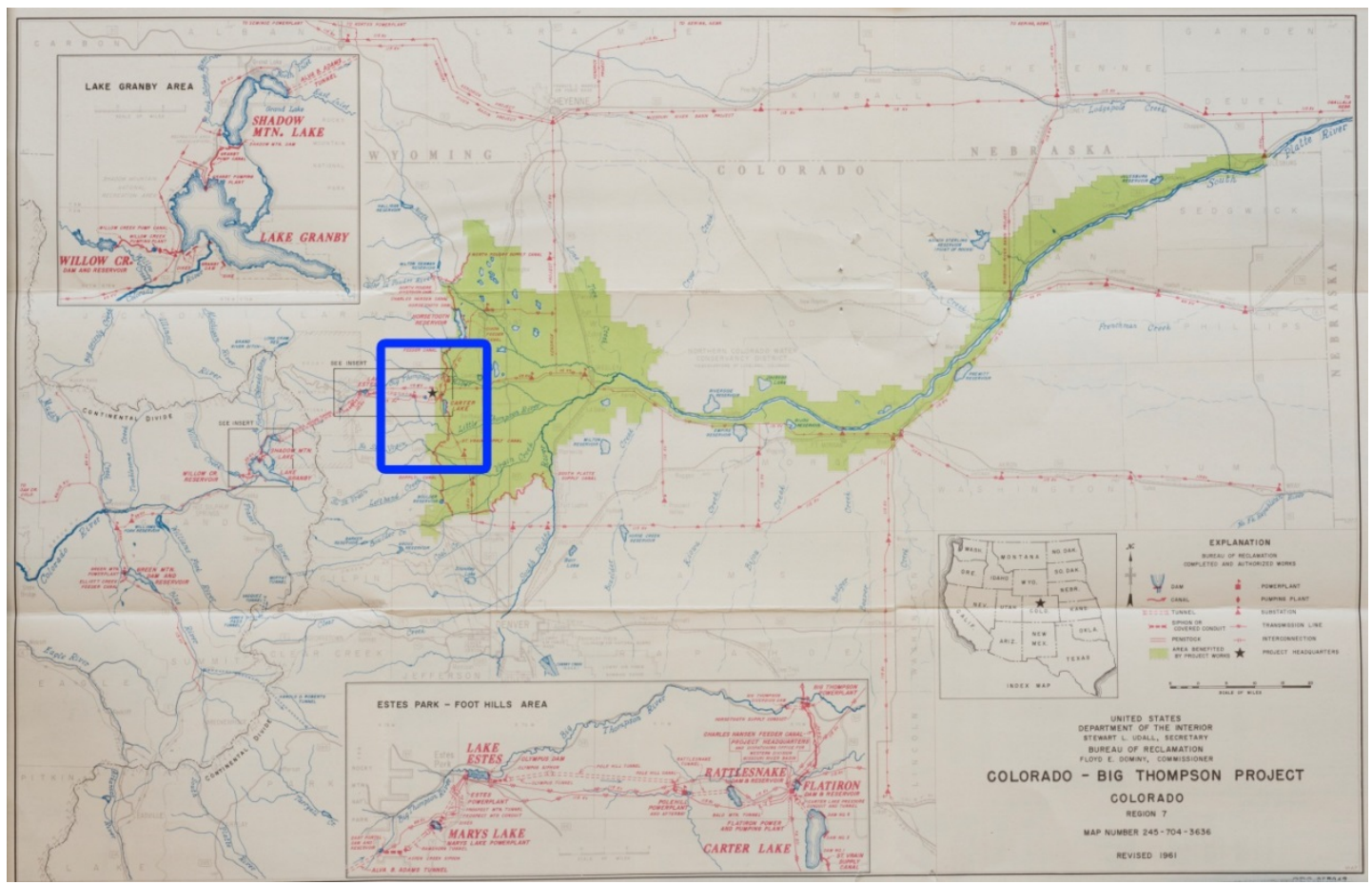

Figure 10. A 15 inches by 9.5 inches map. The blue square indicates the enlarged area for figure 11. Historical map from Colorado State University Archives and Special Collections. 


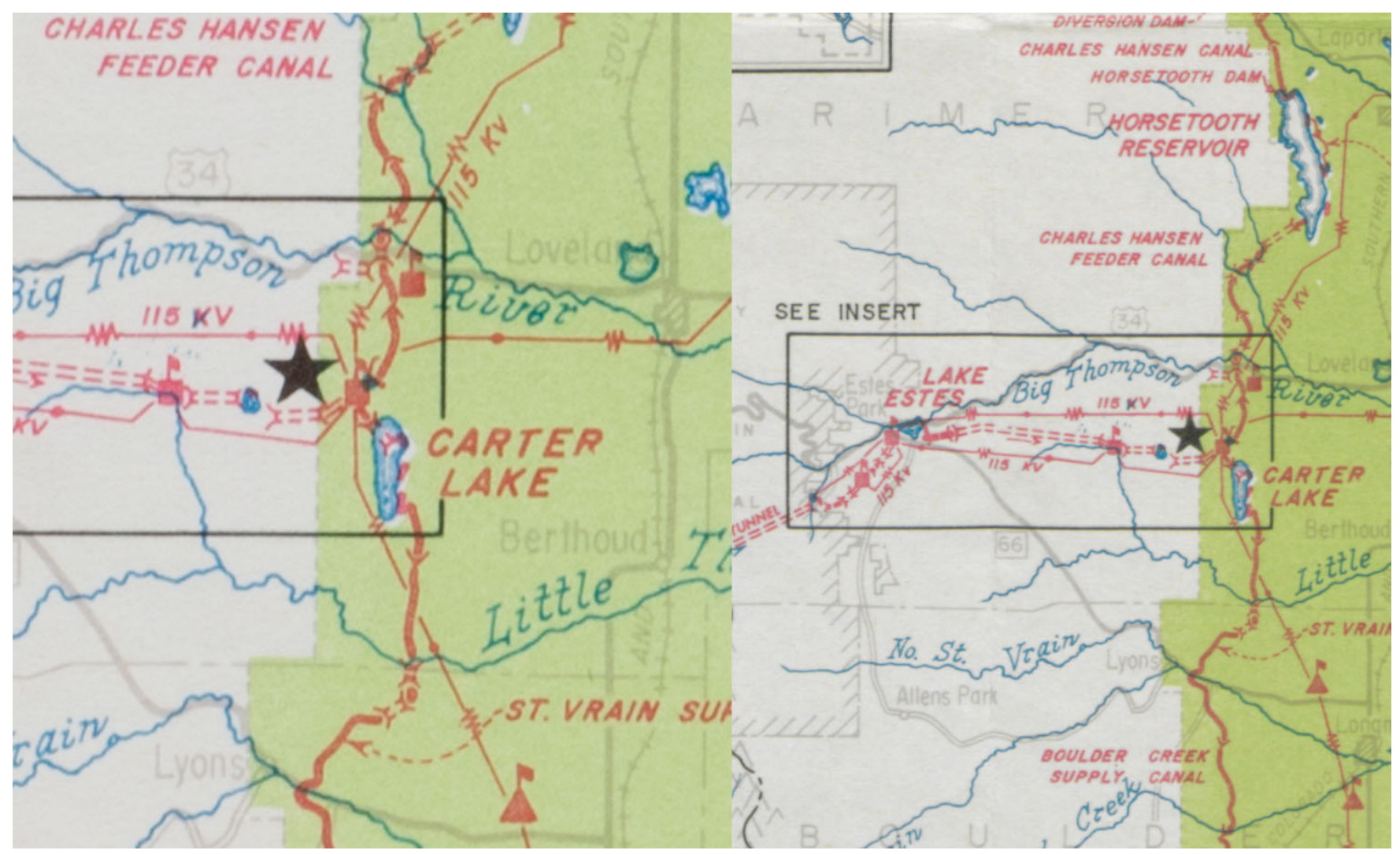

Figure 11. Small Map Screen Views at 100 Percent Zoom. The left image was photographed by a DSLR camera with a macro lens and the right image was produced by our overhead scanner. Historical map from Colorado State University Archives and Special Collections.

\section{Post-Processing}

\section{Use of a Sharpening Filter}

Our tests showed that a main drawback of our overhead scanner is that images produced are outof-focus. Some digitization guidelines recommend minor post-processing for delivered images files to improve image quality. One might argue that to fix our overhead scanner's out-of-focus problem, sharpening can be applied. Technical Guidelines for Digitizing Cultural Heritage Materials: Creation of Raster Image Master Files recommends doing minor post-scan adjustment to optimize image quality and bring all images to a common rendition. ${ }^{1}$ This is good advice, but it is not applicable in real-world practice. To get the best result, each image would need to be evaluated and have a sharpening filter applied separately because when an improper sharpening setting is applied to an image, it often creates haloing artifacts and an unnatural look. The application of a sharpening filter to each image process will be extremely time-consuming.

The haloing artifact is also called chromatic aberration (CA) effect. CA appears as unsightly color fringes near high contrast edges. Chromatic aberrations are typically only visible when viewing the image on-screen at higher zoom levels or on large prints. 
The following example shows that the CA may not appear at lower zoom levels, such as 50 percent or 100 percent. The left image has no sharpening filter applied and the right image has a sharpening filter applied. At 100 percent zoom, chromatic aberration is almost not identifiable, and the right image appears to be superior in turns of sharpness.

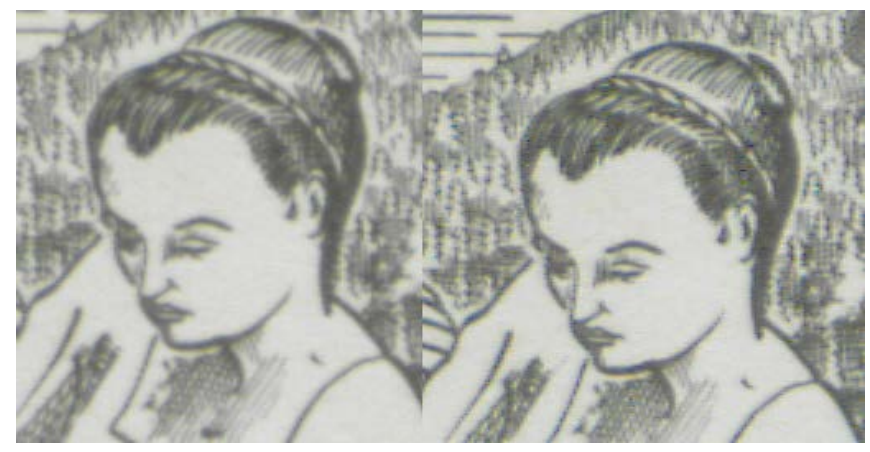

Figure 12. Sharpening Filter Comparison Sample at 100 Percent Zoom. The left image has no sharpening filter applied and the right image has been applied a sharpening filter. Historical map from Colorado State University Archives and Special Collections.

At a higher zoom level, we see CA, visible in the right image of figure 13. The extra colors are introduced by the software.

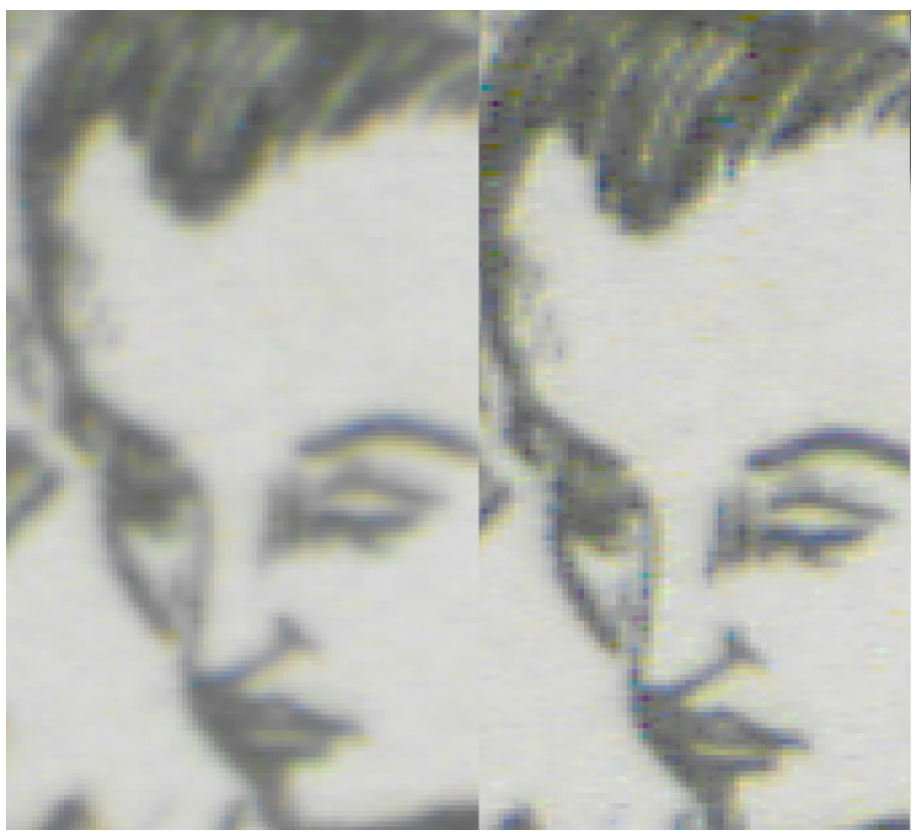

Figure 13. Comparison of Sharpening Filter Applied to Images and at 500 Percent Zoom. The left image has no sharpening filter applied and the right image has sharpening filter applied. Historical map from Colorado State University Archives and Special Collections. 
We recommend not applying sharpening filters to original scanned images; instead, attempt to obtain well-focused images from the beginning. For this reason, the test DSLR camera outperformed our overhead scanner for most materials.

\section{Color Balance}

Have you seen a scanned color image or color photograph with colors very different from the original image? For example, a white area appears to be bluish, or it has an orange cast? When scanning or photographing an image under different lighting, the output image can have very different colors.

In the following figure, the left image was shot at a correct white balance (WB) setting. WB is the process of removing unrealistic color casts so that objects that appear white in person are rendered white in your photo. ${ }^{2}$ The center image has a blue color cast, which was caused by a lower Kelvin setting, and the right image was shot at a higher Kelvin setting. A camera may create images with the wrong colors, but so will a scanner if it is not calibrated correctly.

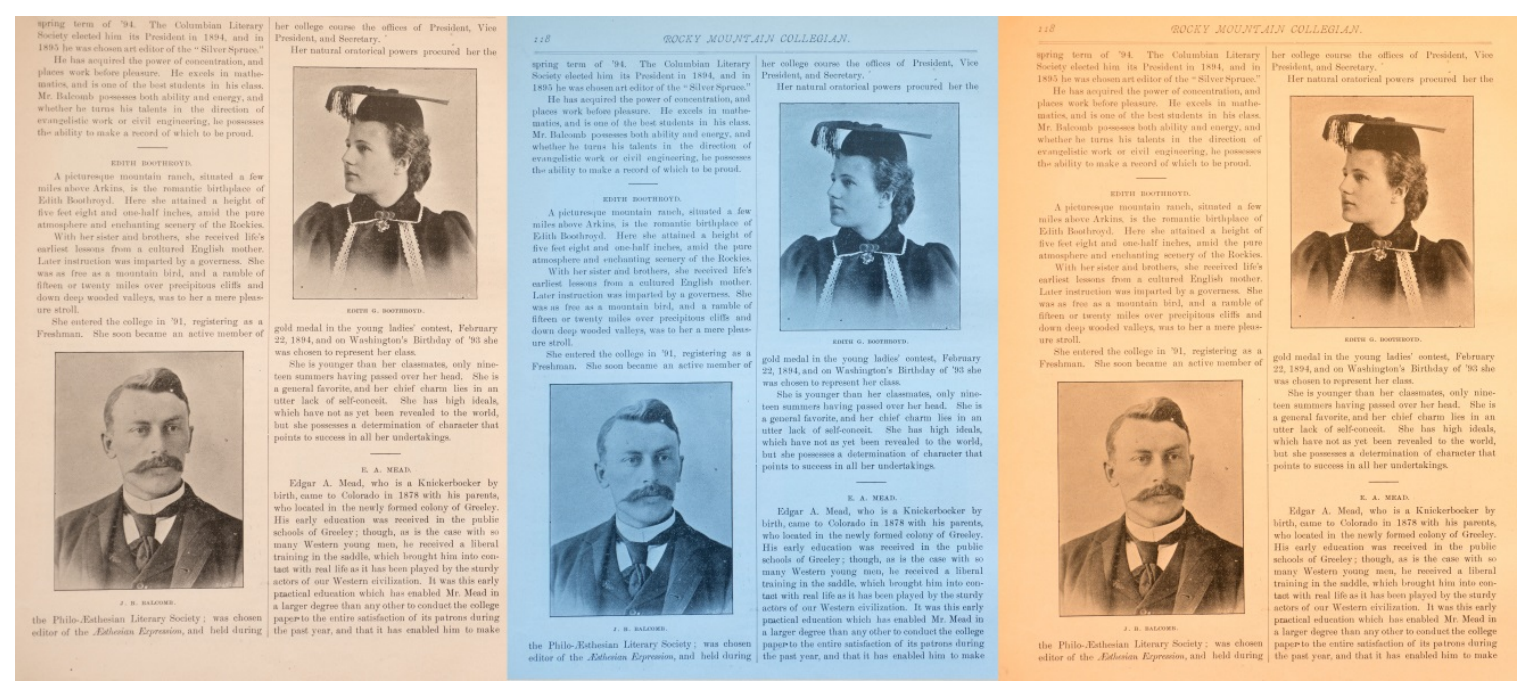

Figure 14. Images Shot under Different White Balance Settings.

We pay an $\$ 8,000$ annual service fee for overhead scanner maintenance, which includes scanner color calibration. In general, image colors rendered by the machine are close to original colors but not exact. We have noticed that some images have a very light green overcast and other others are overly yellow; sometimes images appear to be darker than they should be. Because we are not certified to calibrate the overhead scanner, we only use the prescribed settings set by technicians. Also, we have no control over maintaining a fading light bulb, which will affect correct exposure.

WB adjustment on photographs taken in a studio can be very precise. Most DSLR contains a variety of preset white balances. In general, auto WB works well, but does not deliver the best results. Custom WB allows fine-tuning of colors. If a shooting studio is set up properly, the lighting should be consistent, so ideally one setting found most desirable can be used repeatedly. However, professional photographers do test shots at the beginning of each shooting session. Once they find 
the optimal test shot, they will use the exact settings for the batch. Later, they will do minor color adjustment on the chosen test shot to ensure precise color representation, and then apply the adjustment settings on all other photos of the same batch. Because many small variations can be present for each shooting session, they do not use the settings from the previous shooting. It may seem arduous to do test shots for each shooting, but it ensures accurate color reproduction.

Many professional photographers use ColorChecker Passport, ${ }^{3}$ which is a commercial product to help with quick and easy capture of accurate colors. I will demonstrate briefly a useful trick I learned from a professional photography seminar how to utilize ColorChecker Passport to apply correct white balance a group of images. ${ }^{4}$

Step 1: Place an 18 percent gray card or a ColorChecker Passport card on top of a page. Choose the correct exposure and take the photo. Use the same exposure setting to take additional photos. For demonstration purposes, we deliberately used a very low and high Kelvin setting for sample images. The low Kelvin setting created cool and blue tones and the high Kelvin setting created a tone that was too warm. Note that the test shot with ColorChecker Board was not taken with exactly the correct white balance setting.
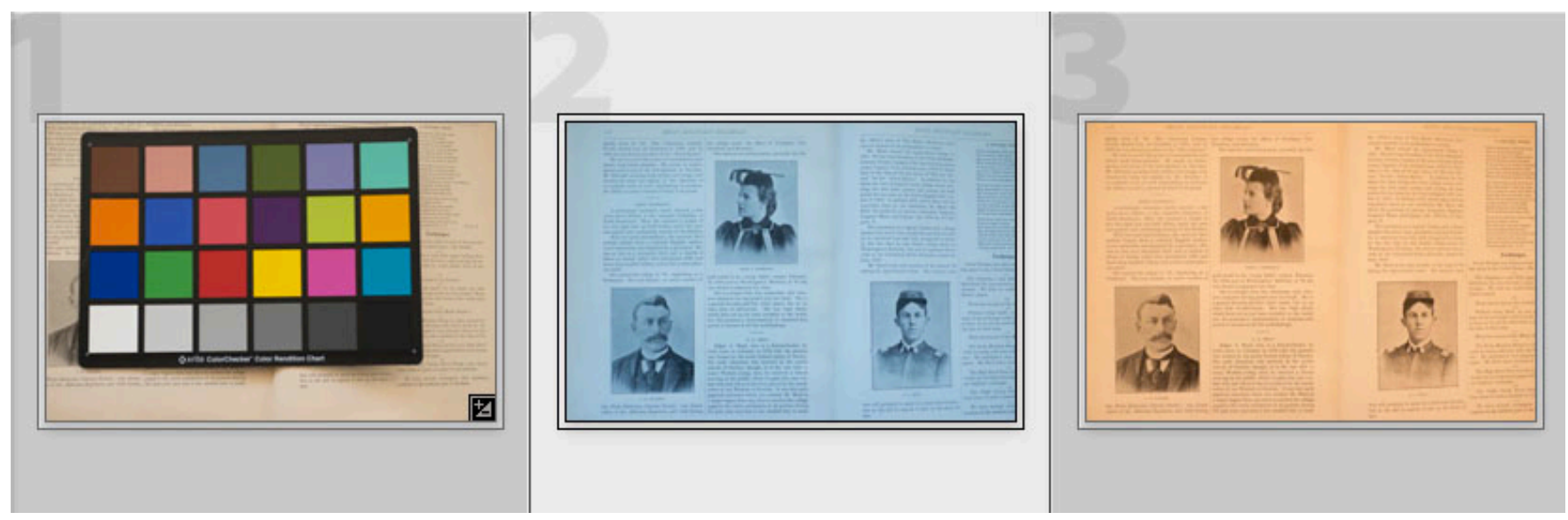

Figure 15. Sample Images for White Balance Adjustment. Rocky Mountain Collegian 3-4 (1893), 118, Colorado State University Archives and Special Collections.

Step 2: In Adobe Lightroom, select the test target image and switch to "Develop" mode. Select the White Balance tool, move the cursor over a gray area, try to find a spot where the red, green, and blue (RGB) values are close. If you can find a place with equal RGB values, it will be ideal. This simple click will set the test image's white balance to an almost perfect setting. 


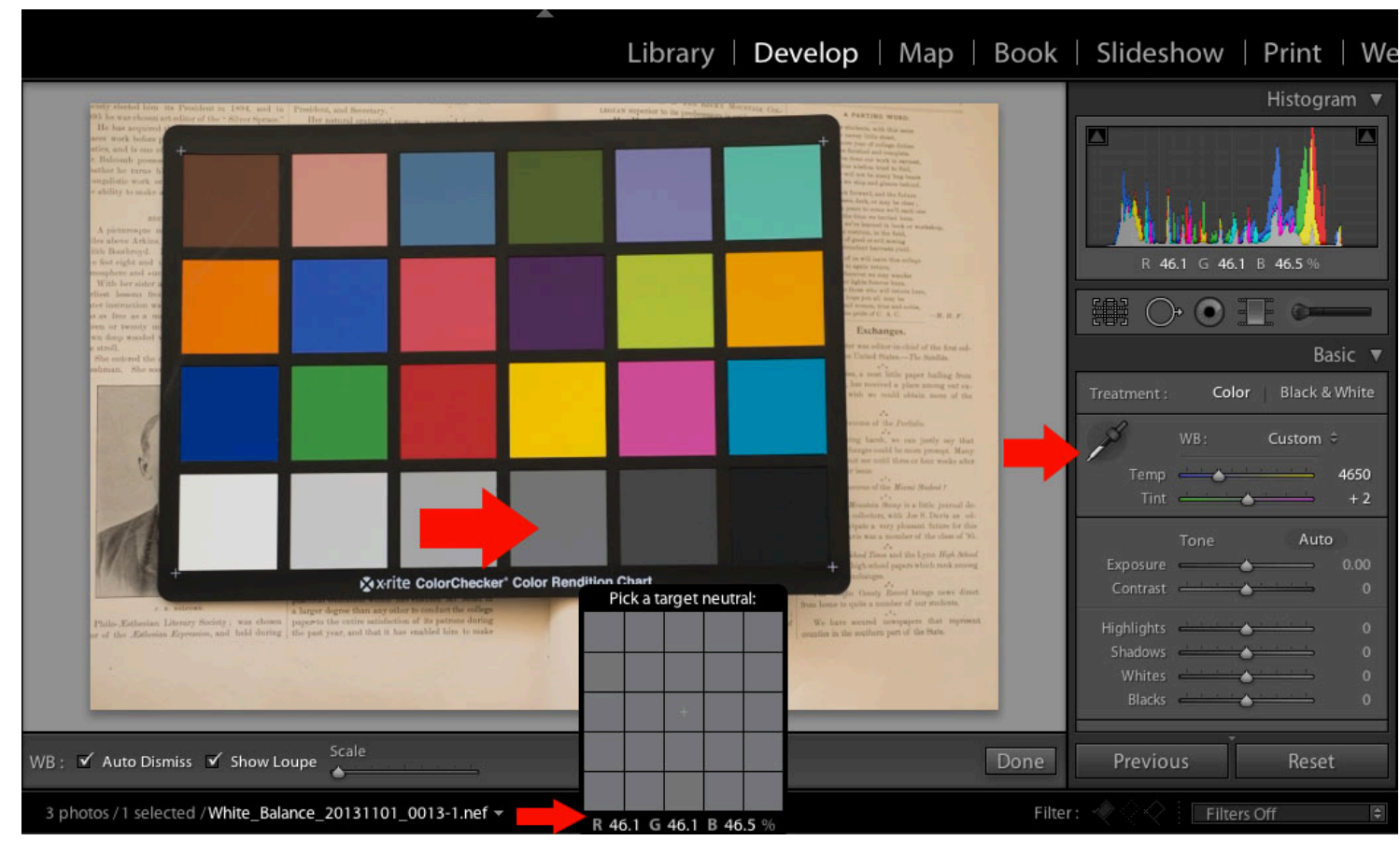

Figure 16. Applying a White Balance in Adobe Lightroom 4

Step 3. Synchronize other images' settings with the target image. Select the target image and all other images, click the Sync button, and select settings you would like to synchronize. Make sure the WB button is checked.

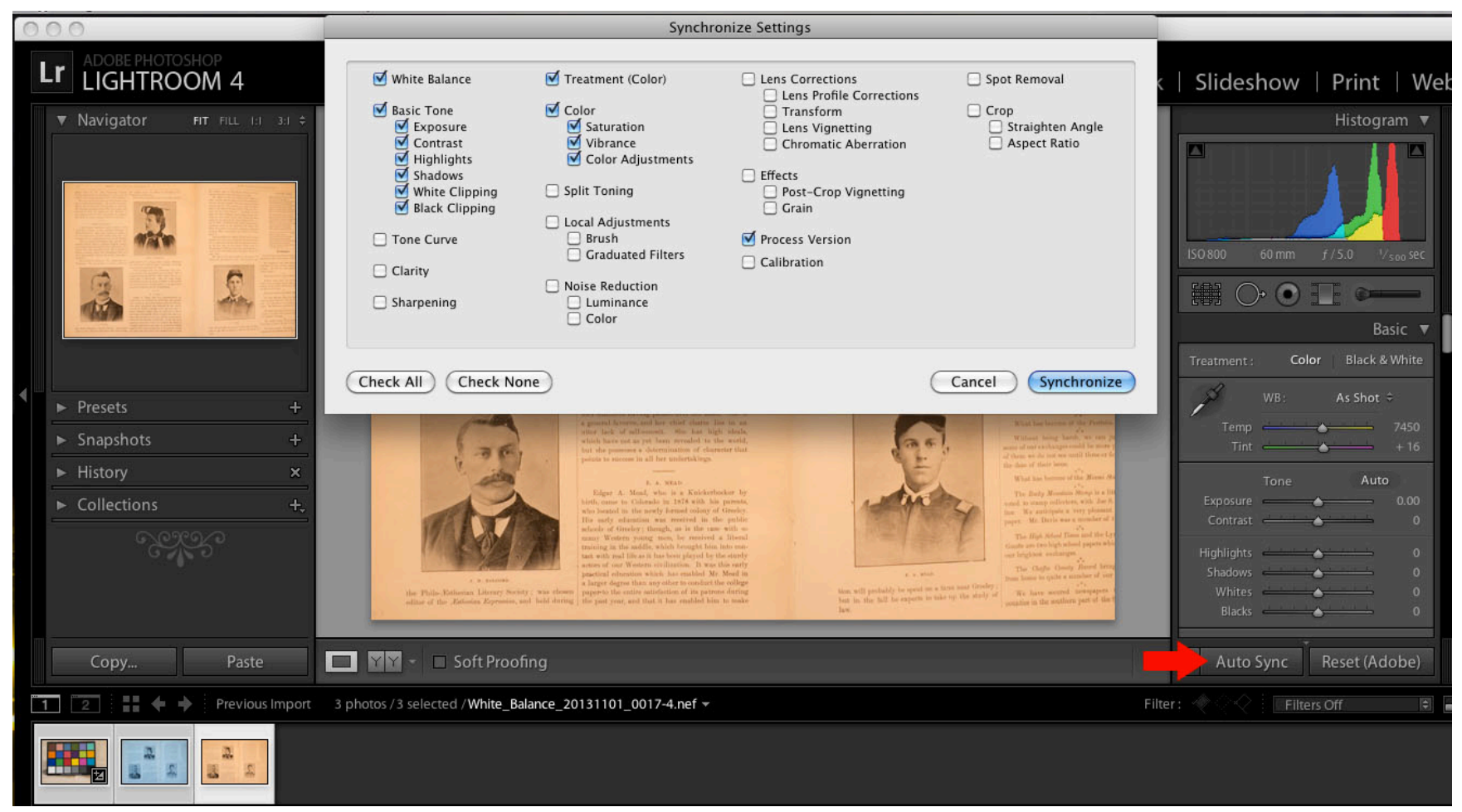

Figure 17. Synchronize Settings in Adobe Lightroom 4 


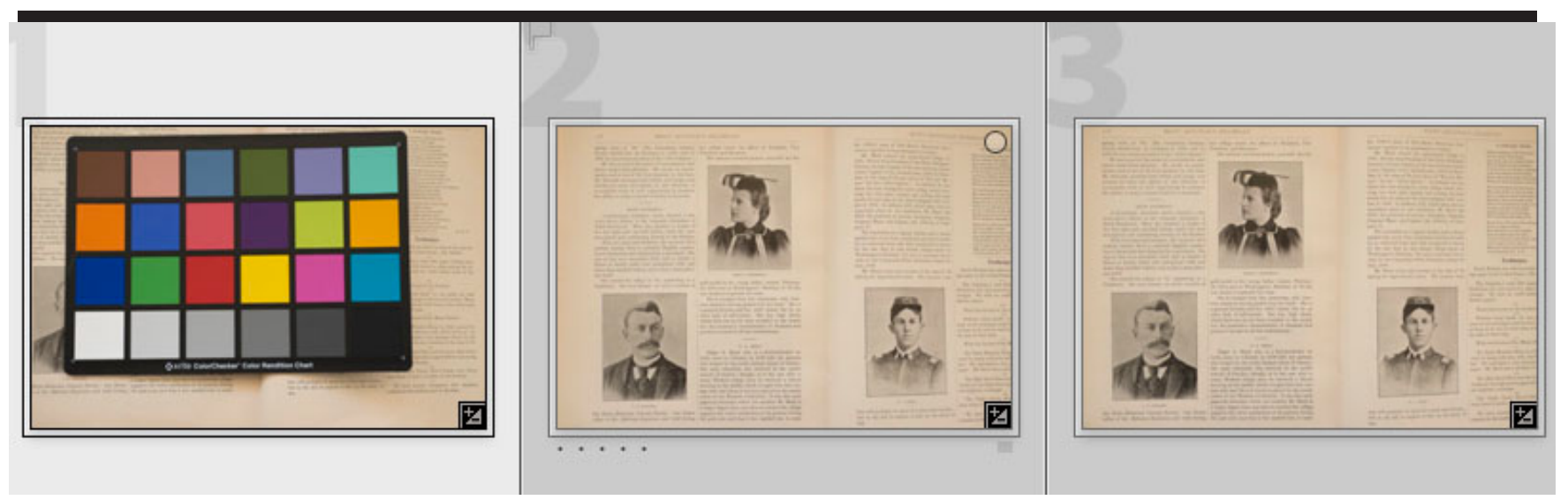

Figure 18. Synchronized Images with Correct White Balance. Rocky Mountain Collegian 3-4 (1893), 118, Colorado State University Archives and Special Collections.

Recently, I had the opportunity to visit the Spencer Museum of Art's digitization lab. They have a different workflow to ensure even more scientifically correct colors. If you are interested in their approach, you can contact their information technology manager or photographer.

\section{Color Space}

One very important thing to understand is color space when you use a DSLR camera. Many DSLR cameras support Adobe RGB and sRGB.

sRGB reflects the characteristics of the average cathode ray tube (CRT) display. This standard space is endorsed by many hardware and software manufacturers, and it is becoming the default color space for many scanners, low-end printers, and software applications. It is the ideal space for web work but not recommended for prepress work because of its limited color gamut.

Adobe RGB (1998) was designed to encompass most of the colors achievable on CMYK printers, but only by using RGB primary colors on a device such as your computer display. ${ }^{5}$ It is recommended to use this color space if you need to do print production work with a broad range of colors. Many scanning vendors deliver images in Adobe RGB color space.

ProPhoto RGB contains all colors that are in Adobe RGB, and Adobe RGB contains nearly every color that is in SRGB. This color space covers more colors than the human eye can see. It can only be used for images in RAW format and in 16-bit mode. Common file formats that support 16-bit images are TIFF and PSD. Most printers do not support 16-bit format. This color space normally is used by photographers who have a specific workflow and who print on specific high-end inkjet printers. When converting from 16-bit to 8-bit, some images will have banding or posterization problems.

Banding is a digital imaging artifact. A picture with banding problem shows horizontal or vertical lines. 


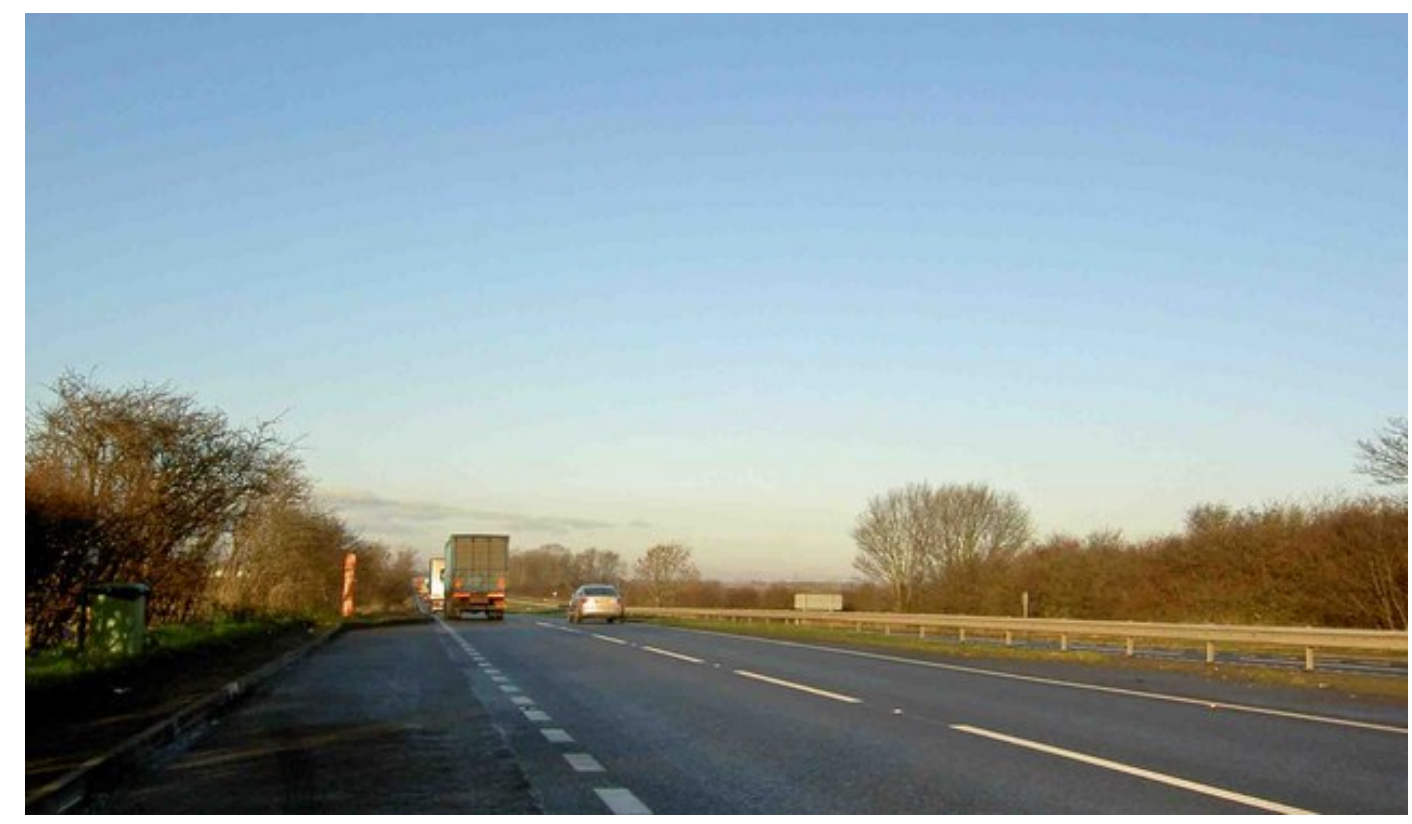

Figure 19. An Example of Colour Banding, Visible in the Sky in This Thotograph. ${ }^{6}$

Posterization of an image entails conversion of a continuous gradation of tone to several regions of fewer tones, with abrupt changes from one tone to another. ${ }^{7}$
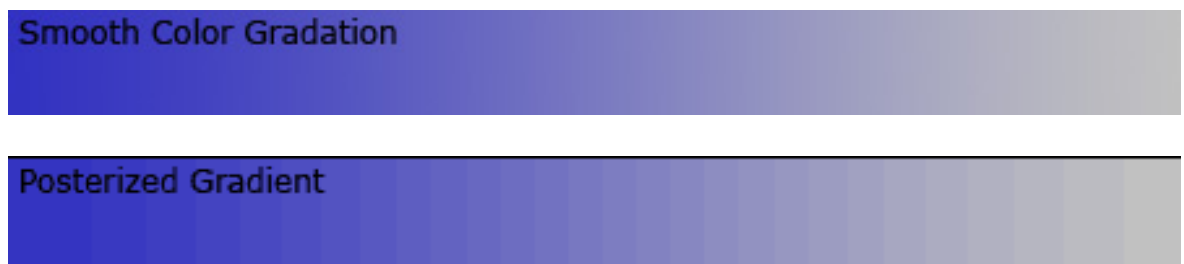

Figure 20. An Example of Posterization. ${ }^{8}$

While it is a good idea to capture images using Adobe RGB to preserve a wide range of colors, you should convert images to sRGB when delivering to unknown users and displaying on the web. Currently, sRGB is the only appropriate choice for images uploaded to the web, since most web browsers don't support any color management. Adobe RGB images that are uploaded to websites without conversion to sRGB generally appear dark and muted. ${ }^{9}$ If they were printed on printers that do not support Adobe RGB format, colors will be dull too.

\section{SETTING UP A BUDGET STUDIO}

\section{Commercial Approach}

BookDrive Pro is a commercially available digitization unit. It uses two digital cameras and built-in flash lights. It may be the optimal solution for your projects, but it also may not fit your library's 
budget. The unit also is not suitable for oversized material such as large maps and posters. For more information about this product, please visit http://pro.atiz.com/.

\section{Sample Budget Studio Setup}

A digitization lab can have three rooms or areas, one for oversized materials, one for smaller prints or 3-D objects, and one for computers.

The area for shooting oversized materials should have black walls and floor. You can either use one flash light to bounce light off the ceiling or use two flash lights to shine lights directly onto the materials. For fragile materials, the first approach is more appropriate.

The area for shooting smaller prints or 3-D objects should have a stable table and black or white background paper. For this room or area, black walls and floor are not required.

For shooting equipment, I will use the set chosen by the photographer from the University of Kansas Spencer Museum of Art as my example.

\begin{tabular}{|c|c|c|c|}
\hline Item Name & Sample Item & Purchasing URL & Price \\
\hline DSLR camera & Nikon D810 & $\begin{array}{l}\underline{\text { http://www.bhphotovideo.co }} \\
\text { m/c/search?atclk=Camera+Mo } \\
\underline{\text { del Nikon+D810\&ci }=6222 \& N=} \\
\underline{4288586280+3907353607}\end{array}$ & $\$ 2,996.95$ \\
\hline Macro lens & $\begin{array}{l}\text { Nikon AF Micro-Nikkor } \\
60 \mathrm{~mm} \mathrm{f/2.8D} \mathrm{Lens}\end{array}$ & $\begin{array}{l}\text { http://www.bhphotovideo.co } \\
\text { m/c/product/66987- } \\
\text { GREY/Nikon } 1987 \text { AF Micro } \\
\text { Nikkor 60mm f } 2 \text { 8D.html }\end{array}$ & $\$ 429.00$ \\
\hline Heavy duty mono stand & $\begin{array}{l}\text { Arkay 6JRCW Mono Stand } \\
\text { Jr with Counter Weight- } \\
6^{\prime}\end{array}$ & $\begin{array}{l}\text { http://www.bhphotovideo.co } \\
\text { m/c/product/2727- } \\
\text { REG/Arkay 605138 6JRCW M } \\
\text { ono Stand Ir.html }\end{array}$ & $\$ 678.50$ \\
\hline Strobe & $\begin{array}{l}\text { Broncolor G2 Pulso- } \\
1600 \text { Watt/Second } \\
\text { Focusing Lamphead with } \\
16 \text { ' Cord }\end{array}$ & $\begin{array}{l}\text { http://www.bhphotovideo.co } \\
\text { m/c/product/259745- } \\
\underline{\text { REG/Broncolor } 3211507 \text { G2 }} \\
\text { Pulso with } 16 . h \mathrm{tml}\end{array}$ & $\$ 3,053.68$ \\
\hline Power pack & $\begin{array}{l}\text { Broncolor Senso A4 } \\
2,400 \mathrm{~W} / \mathrm{s} \text { Power Pack }\end{array}$ & $\begin{array}{l}\text { http://www.bhphotovideo.co } \\
\text { m/c/product/745060- } \\
\underline{\text { REG/Broncolor } 3105107 \text { Se }} \\
\text { nso A4 } 2400 \mathrm{~W} \text { s Power.html }\end{array}$ & $\$ 3,629.92$ \\
\hline
\end{tabular}




\begin{tabular}{|c|c|c|c|}
\hline Reflector & $\begin{array}{l}\text { Broncolor P65 Reflector, } \\
65 \text { Degrees, 11" } \\
\text { Diameter, for Broncolor } \\
\text { Pulso 8, Twin and HMI }\end{array}$ & $\begin{array}{l}\text { http://www.bhphotovideo.co } \\
\text { m/c/product/7162- } \\
\text { REG/Broncolor } 3310600 \text { P6 } \\
\underline{5 \text { Reflector } 65 \text { Degrees.html }}\end{array}$ & $\$ 513.52$ \\
\hline Reflector & $\begin{array}{l}\text { Broncolor Softlight } \\
\text { Reflector, 20" Diameter, } \\
\text { for Broncolor Primo, } \\
\text { Pulso 2/4 \& HMI Heads }\end{array}$ & $\begin{array}{l}\text { http://www.bhphotovideo.co } \\
\text { m/c/product/7167- } \\
\text { REG/Broncolor } 3311000 \text { Sof } \\
\text { tlight Reflector } 20 \text { for.html }\end{array}$ & $\$ 501.76$ \\
\hline Light Stand & $\begin{array}{l}\text { Impact Air-Cushioned } \\
\text { Light Stand }\end{array}$ & $\begin{array}{l}\text { http://www.bhphotovideo.co } \\
\text { m/c/product/253067- } \\
\text { REG/Impact LS10AB Air Cush } \\
\underline{\text { ioned Light Stand.html }}\end{array}$ & $\$ 44.99$ \\
\hline Light meter & $\begin{array}{l}\text { Sekonic L-308S } \\
\text { Flashmate-Digital } \\
\text { Incident, Reflected and } \\
\text { Flash Light Meter }\end{array}$ & $\begin{array}{l}\text { http://www.bhphotovideo.co } \\
\text { m/c/product/368226- } \\
\text { REG/Sekonic 401309 L 308S } \\
\text { Flashmate Light Meter.html }\end{array}$ & $\$ 199.00$ \\
\hline Book cradle & Book Exhibition Cradles & $\begin{array}{l}\text { http://www.universityproduct } \\
\text { s.com/cart.php?m=product list } \\
\underline{\text { \&c=1115\&primary=1\&parentI }} \\
\underline{\mathrm{d}=1271 \text { \&navTree[] }=1115}\end{array}$ & $\$ 30.00$ \\
\hline Background paper & $\begin{array}{l}\text { Savage Seamless } \\
\text { Background Paper (Both } \\
\text { white and black) }\end{array}$ & $\begin{array}{l}\text { http://www.bhphotovideo.co } \\
\text { m/c/product/45468- } \\
\underline{\text { REG/Savage } 112107 \text { x 12yd }} \\
\underline{\text { s Background.html }}\end{array}$ & $\begin{array}{l}\$ 45.00 x \\
2= \\
\$ 90.00\end{array}$ \\
\hline Nonreflective glass & $\begin{array}{l}\text { 1/4" Optiwhite Starphire } \\
\text { Purified Tempered Single } \\
\text { Lite Clear Class }\end{array}$ & $\begin{array}{l}\text { Can be purchased at local glass } \\
\text { store. }\end{array}$ & $\$ 75.00$ \\
\hline $\begin{array}{l}\text { White balancing } \\
\text { accessory }\end{array}$ & $\begin{array}{l}\text { X-Rite Original } \\
\text { ColorChecker Card }\end{array}$ & $\begin{array}{l}\text { http://www.bhphotovideo.co } \\
\text { m/c/product/465286- } \\
\text { REG/X Rite MSCCC Original C } \\
\text { olorChecker Card.html }\end{array}$ & $\$ 69.00$ \\
\hline Software & Adobe Lightroom 5 & $\begin{array}{l}\text { http://www.adobe.com/produ } \\
\text { cts/photoshop-lightroom.html }\end{array}$ & $\$ 150.00$ \\
\hline
\end{tabular}

Table 3. List of Items Needed to Prepare for a Budget Studio

The total cost for a "budget" shooting studio ranges from $\$ 10,000$ to $\$ 15,000$, and there is no annual maintenance expense. 


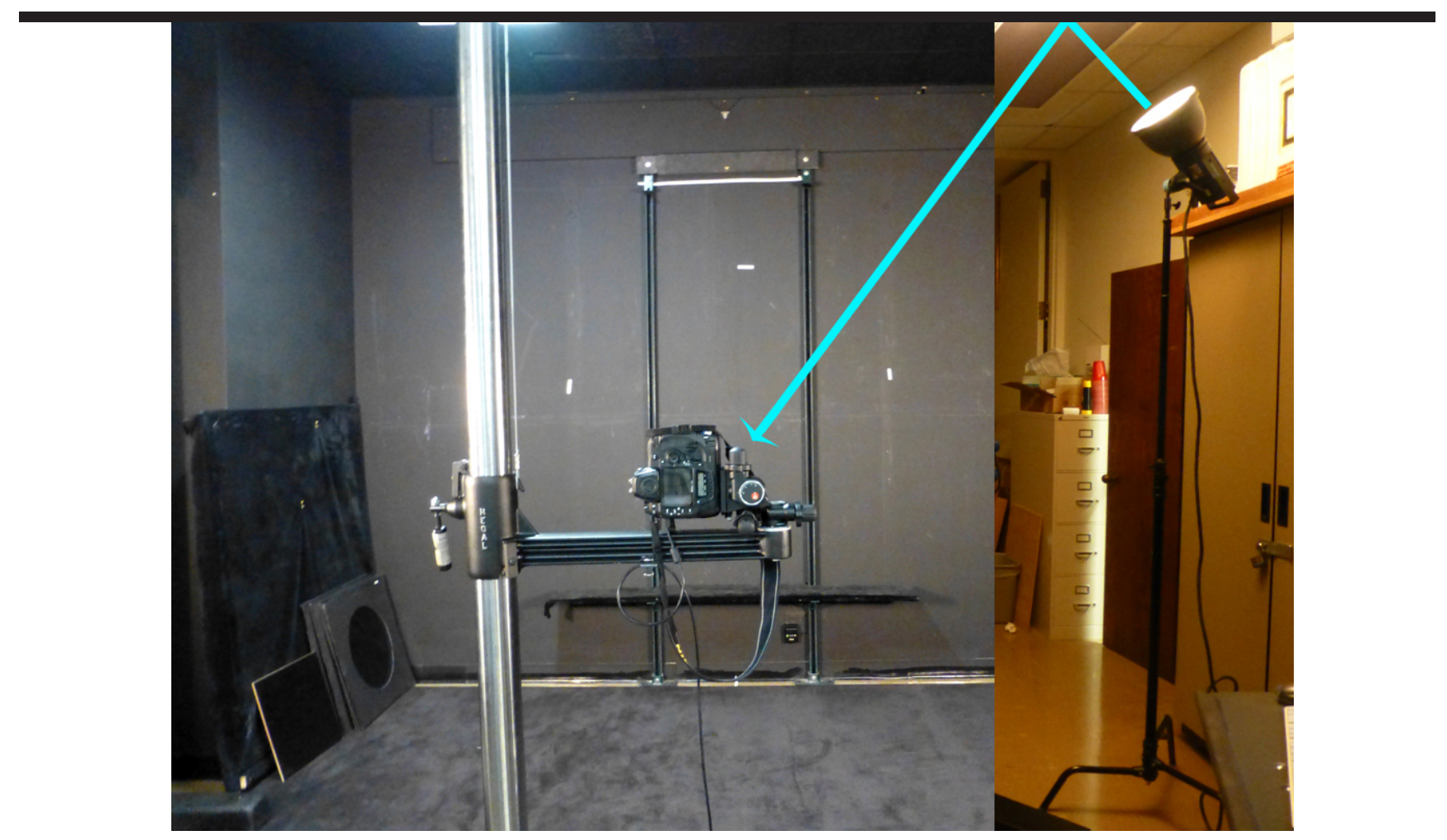

Figure 21. The University of Kansas Spencer Museum of Art Digitization Lab Setup for Oversized Materials

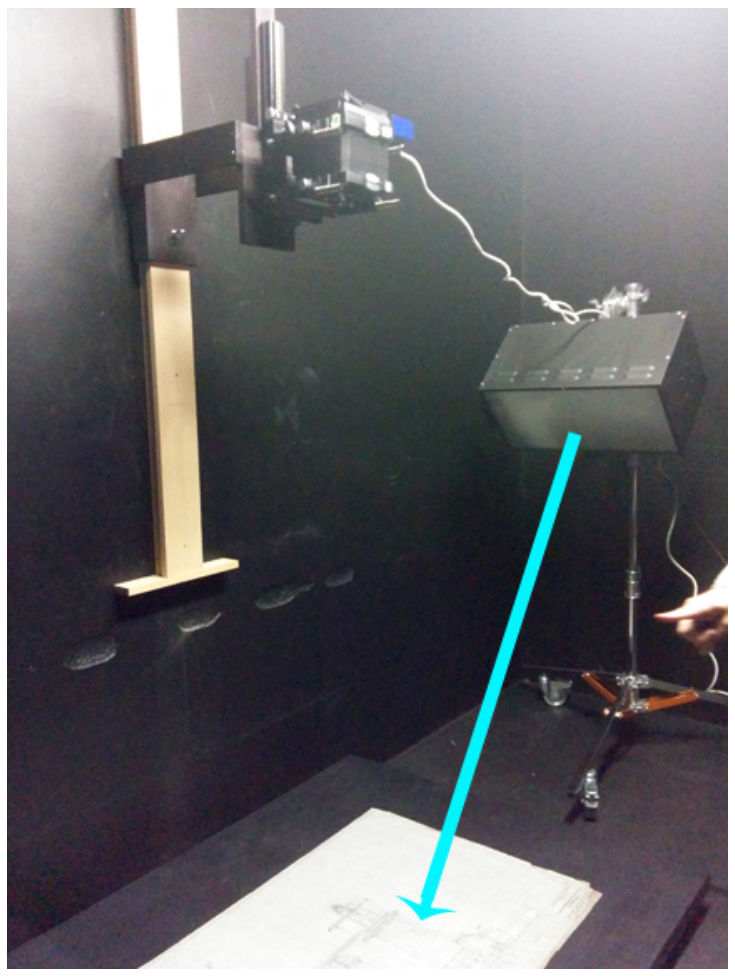

Figure 22. Steelworks Museum of Industry and Culture's Digitization Lab Setup for Oversized Materials 


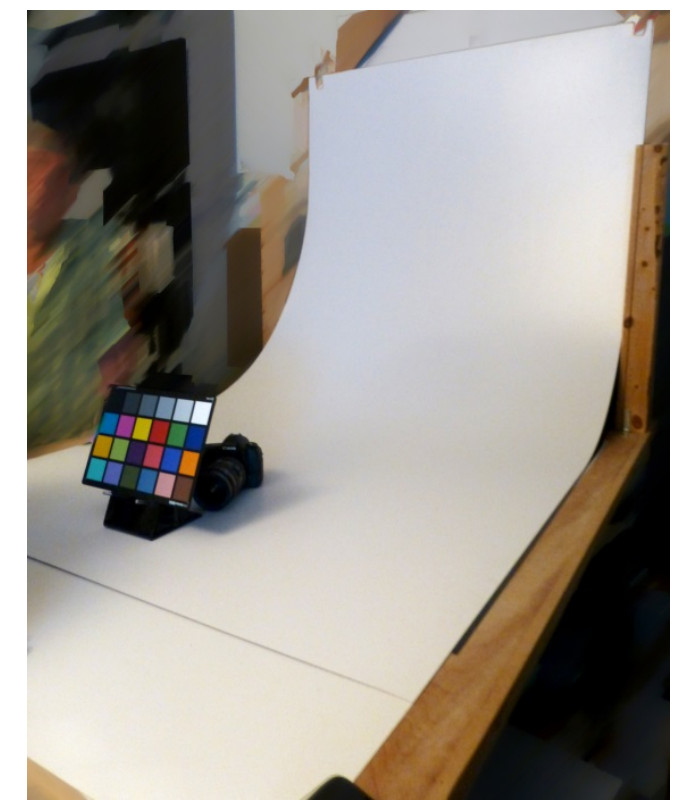

Figure 23. The University of Kansas Spencer Museum of Art Digitization Lab Setup for Smaller Prints and 3-D Objects

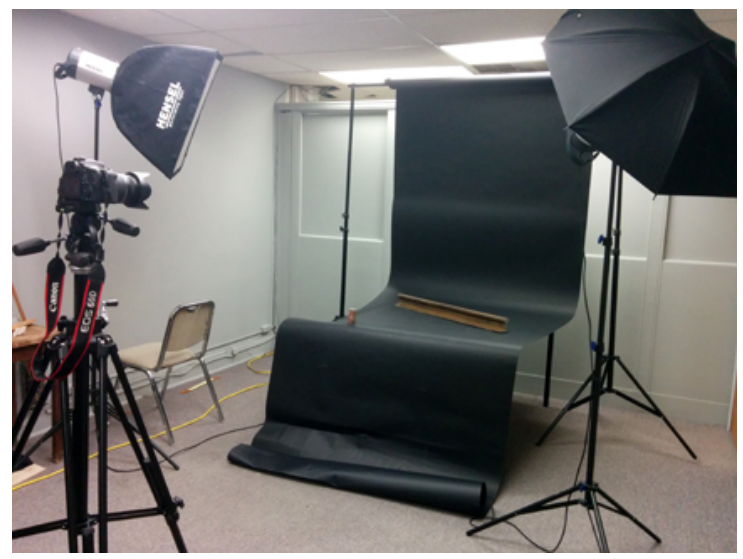

Figure 24. Steelworks Center of the West's Digitization Lab Setup for 3-D Objects

\section{Functions of Some Elements in the Sample Shooting Studio}

1. Macro Lens: It allows close up shooting of objects. It is especially useful when photograph small prints and small 3-D objects. It can also be used to photograph regular and oversized materials.

2. Heavy-duty mono stand: It replaces a traditional tripod. It is very stable and allows quick adjustment of camera height and location.

3. Strobe, power pack, and reflector: Together they generate consistent and homogeneous light distribution. Recommended further reading: "Introduction to OffCamera Flash: Three Main Choices in Strobe Lighting." 10

4. Light stand: It holds strobe and reflector. 
5. Light meter: Hand-held exposure meters measure light falling onto a light-sensitive cell and converts it into a reading that enables the correct shutter speed and or lens aperture settings to be made. ${ }^{11}$

6. Book cradles: They help to minimize the stress on bookbindings and minimize page curvature problem.

7. Nonreflective glass: It helps to flatten a photographed page and reduce the reflection. However, it does not completely eliminate glass reflection. One very useful trick to reduce glass reflection is to place a black board with a hole above a page and shoot through the hole. This approach actually does not eliminate reflection but reflects black to the photograph. When the photograph is reviewed on computer, it will appear as no reflection has occurred.

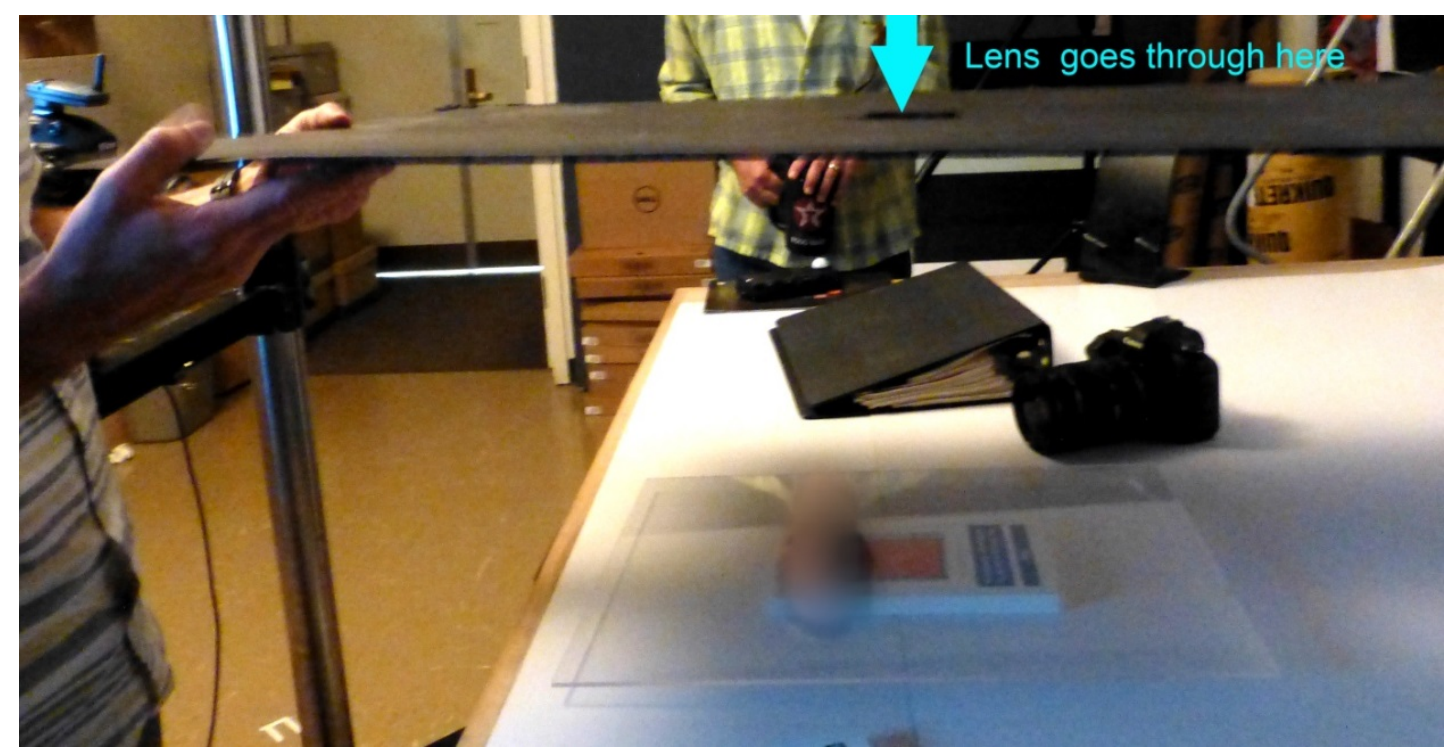

Figure 25. The University of Kansas Spencer Museum of Art Digitization Lab Setup for Materials Needed be Pressed Down by a Glass.

Many librarians believe that digitizing print materials using a digital camera requires a professional photographer, but this is not necessarily true. A professional photographer or even an art student can act as a consultant to help set up a shooting studio and provide basic training. Also, many museums have professional photographers and have set up shooting studios for digitization. They are very willing to share their experience and even provide training. I believe the learning curve for operating a shooting studio is no greater than the learning curve to operate an overhead scanner machine and its software.

\section{PROS AND CONS}

No digitization equipment or system is perfect. They all have trade-offs in image quality, speed, convenience of use, quality of accompanying software, and cost. Our tests show that for most archival materials a DSLR camera will do a better job than an overhead scanner.

\section{Pros of Overhead Scanner}


- The scanner is a complete scanning station. It can be connected to a computer and starts scanning immediately. Materials can be placed on the scanning surface, so no equipment adjustments are required while scanning.

- It can scan and save images in bitmap format directly, while a DSLR camera can only shoot in grayscale or color.

- Built-in book cradles help to scan thick books and those that cannot be fully opened.

- Book curve correction functionality is provided by the accompanying software.

\section{Cons of Overhead Scanner}

- High cost. The overhead scanner we have cost more than $\$ 50,000$, with an annual maintenance contract of $\$ 8,000$.

- High replacement cost. When a scanner is outdated or broken, the entire machine has to be replaced.

- Instability. Our overhead scanner is unstable even when placed on a sturdy table and handled only by professionals. From April 2010 to October 2010, the scanner was down for a total of forty-two working days (sixty calendar days). The company fixed the machine onsite many times, but it continues to have minor problems and has not been completely reliable.

- The autofocus feature does not work consistently.

- Special training is needed to operate the machine and associated software.

- File formats supported are limited. Most scanners only support TIFF, JPEG, JPEG 2000, Windows BMP, and PNG.

- Unsupported outdated software: Our overhead scanner's software can only be run on an older operating system (Windows XP) because there is no updated software for this model.

\section{Pros of Budget Studio}

- Stable. Under normal use DSLR cameras are much less likely to break down than scanners. For example, I have had an older DSLR, Nikon D200, for seven years. It has survived numerous backpacking trips, multiple drops, and extreme weather conditions. The camera still functions as needed.

- Fast and accurate focus. DSLR cameras are designed to focus quickly, and their focus indicators provide instant feedback to the operators so they know that the image is focused. If operated properly, images delivered by DSLR cameras can be sharper than ones delivered by scanners.

- Less expensive. A good quality DSLR camera and a lens can be purchased for fewer than $\$ 4,000$ and last for years. As technologies advance, DSLR cameras' prices will continue to drop.

- Ability to save files in more formats. In addition to TIFF and JPEG formats, most DSLR cameras can save photos in RAW file format. Some cameras can directly save images in Digital Negative (DNG) format, and others deliver images in proprietary formats that can be 
converted into DNG using a computer program. Editing RAW images is nondestructive, while editing of TIFF and JPEG images is irreversible.

- Accurate WB and exposure. By using right shooting and post-processing techniques, photographs can have exact color reproduction. On the other hand, calibrating an overhead scanner most likely can only be performed by a company's trained technician. Proper exposure and WB are not guaranteed.

- The RAW file format usually provides more dynamic range. Overexposed and underexposed images can be fixed by adjusting exposure compensation via software; thus lost shadow or highlight detail can be restored.

- Can photograph 3-D objects. Archival collections often have materials other than books, such as art pieces. These materials are better to be photographed than scanned.

- Versatile. Cameras can perform on-site digitization, while overhead scanners are too bulky to be moved around.

- Faster and better preview. Images can be viewed instantly on a computer when proper software, such as Adobe Lightroom, is used. Operators can compare multiple shoots on a screen side-by-side and decide which photo to retain.

- More accessible technical support. The number of DSLR camera users is much higher than overhead scanner users. Technical questions can often be answered through online forums.

- Easy to find replacement parts. When a piece in a shooting studio break down, it is easy to find replacement piece and replace by staff.

- Easy software updates. Software used in a studio is independent from equipment.

\section{Cons of Budget Studio}

- There is learning curve for setting up a shooting studio, operating the studio, and mastering new image processing techniques.

- A DSLR camera with a lower pixel setting will not be sufficient for scanning large-format materials, such as posters and maps.

- No built-in book curve correction is provided by Adobe Photoshop or Lightroom. However, our experience proves that the automatic book curve function does not always work well. We normally use a home-made book cradle to help lay a page flat and use one or two weights to hold down the other side of book. For some books, if flatness is hard to achieve, we place a piece of glass on the top to ensure the flatness.

- Security concern: Since a DSLR camera is highly portable, it can be stolen easily. 


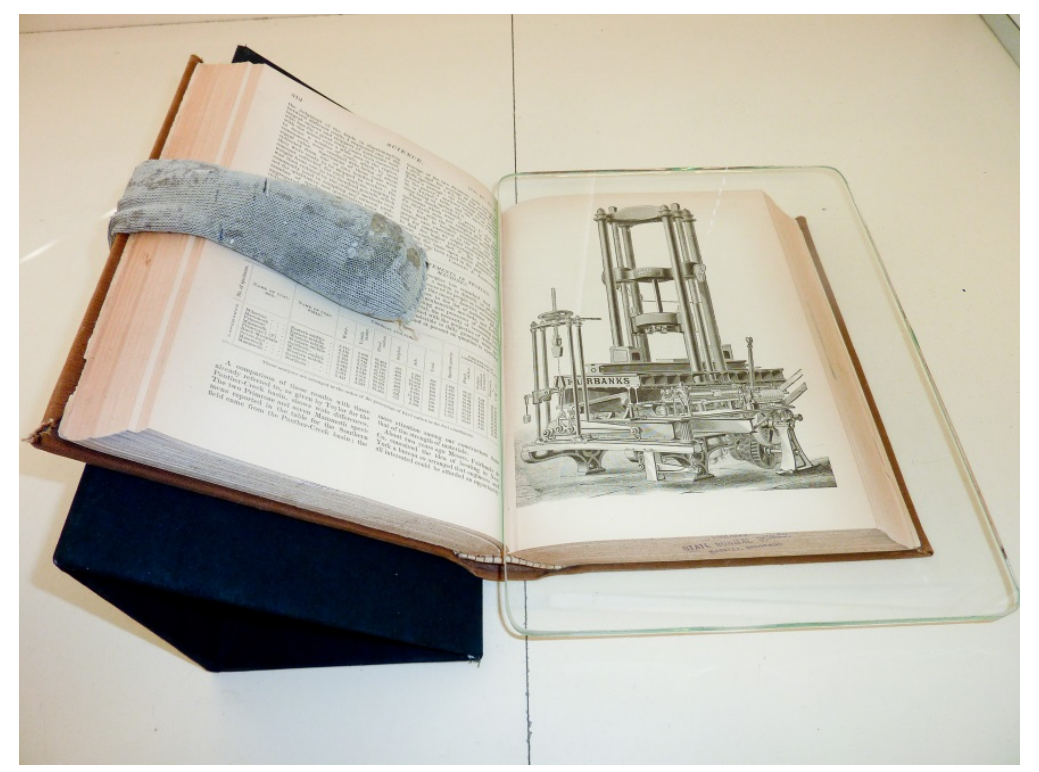

Figure 26. Scanning Setup Using a Book Cradle.

\section{CONCLUSION}

The technology of DSLR cameras has advanced very quickly in the past ten years. Newer DSLR cameras can handle higher resolutions and have very little image noise even at a high ISO setting. The higher demand for DSLR cameras and accompanying image-editing software results in more rapid technology advances compared to low-demand and high-end overhead scanners. High consumer demand drives DSLR camera prices much lower than prices for overhead scanners. In addition, the wide range of consumers purchasing DSLR cameras and software prompts companies to offer more user-friendly interfaces. As you can see from our tests, for most library materials a DSLR camera can produce superior images. If you do not have a budget for high-end overhead scanners, you can still fulfill your digitization preservation goals with a budget studio.

\section{ACKNOWLEDGEMENT}

I would like to thank Robert Hickerson and Ryan Waggoner, the University of Kansas Spencer Museum of Art, Tim Hawkins, and Steelworks Center of the West for showing their digitization labs and sharing experience with me.

\section{REFERENCES}

1. Federal Agencies Digitization Guidelines Initiative, “Technical Guidelines for Digitizing Cultural Heritage Material: Creation of Raster Image Master Files," August 2010, http://www.digitizationguidelines.gov/guidelines/digitize-technical.html

2. “Tutorials: White Balance," Cambridge in Colour, accessed March 9, 2016, http://www.cambridgeincolour.com/tutorials/white-balance.htm. 
3. “ColorChecker Passport User Manual,” X-Rite Incorporated, accessed March 9, 2016, http://www.xrite.com/documents/manuals/en/ColorCheckerPassport User Manual en.pdf.

4. Scott Kelby, “Scott Kelby's Editing Essentials: How to Develop Your Photos,” Pearson Education, Peachpit, accessed March 9, 2016, http://www.peachpit.com/articles/article.aspx?p=2117243\&seqNum=3.

5. “sRGB vs. Adobe RGB 1998," Cambridge in Colour, accessed March 9, 2016, http://www.cambridgeincolour.com/tutorials/sRGB-AdobeRGB1998.htm.

6. “Colour Banding," Wikipedia, accessed March 9, 2016, http://en.wikipedia.org/wiki/Colour banding.

7. “Posterization,” Wikipedia, accessed March 9, 2016, http://en.wikipedia.org/wiki/Posterization.

8. “Image Posterization," Cambridge in Colour, accessed March 9, 2016, http://www.cambridgeincolour.com/tutorials/posterization.htm.

9. Richard Anderson and Peter Krogh, "Color Space and Color Profiles," American Society of Media Photographers, accessed March 9, 2016, http://dpbestflow.org/color/color-space-andcolor-profiles.

10. Tony Roslund, "Introduction to Off-Camera Flash: Three Main Choices in Strobe Lighting," Fstoppers (blog), accessed March 9, 2016, https://fstoppers.com/originals/introductioncamera-flash-three-main-choices-strobe-lighting-40364.

11. "Introduction to Light Meters," B \& H Foto \& Electronics Corp., accessed March 9, 2016, http://www.bhphotovideo.com/find/Product Resources/lightmeters1.jsp. 